\title{
Bor nitrür nanoplateletlerin ve nano Ag takviyeli yapısal yapıştırıcıların kayma dayanımı
}

\author{
Mürsel Ekrem*
}

Necmettin Erbakan Üniversitesi, Mühendislik ve Mimarlık Fakültesi, Makine Mühendisliği Bölümü, Konya, Türkiye, ORCID ID orcid.org/0000-0001-5324-7929

\section{MAKALE BÍLGISI}

Makale geçmişi:

İlk gönderi 20 Mayıs 2019

Revize gönderi 10 Eylül 2019

Kabul 11 Eylül 2019

Online 30 Eylül 2019

\section{Araştırma Makalesi}

DOI: 10.30728/boron.568138

Anahtar kelimeler:

Tek taraflı bindirmeli bağlantı,

Kayma dayanımı,

Nanoparçacık

Hibrid nanoyapıştırıcı.

\section{ÖZET}

Bu çalışmada, hava araçlarında kullanılan farklı bileşenli yapıların hibrid nanoparçacık takviyesiyle epoksi yapıştırıcıların kayma dayanımları araştırılmıştır. 8 kat $0^{\circ} / 90^{\circ}$

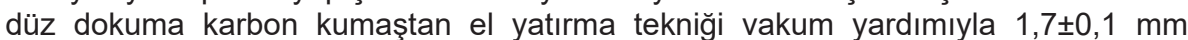
kalınlığında üretilmiştir. Üretilen karbon elyaf takviyeli epoksi kompozitler (KETEK) ile 2024-T3 Alüminyum (Al) levhalar modifiye edilmiş epoksi yapıştırıcılarla tek taraflı bindirmeli bağlantı olarak ASTM D1002-10 standartlarına göre test edilmiştir. Al 2024-T3 malzeme ASTM D3933-98 fosforik asit anotlama ve KETEK numuneler ise ASTM D2093-03 standartlarına göre yüzey hazırlama yöntemleri kullanılmıştır. Epoksi reçineye ağırlıkça \%0,5 Bor Nitrür Nanoplateler (BNNPs) ile ağırlıkça farklı oranlarda $(\% 0,5,1,0$ ve 1,5) nano gümüş $(\mathrm{Ag})$ parçacıkları ilave edilmiştir. Hibrid nano yapıştırıcılar ile referans numunelerin kayma dayanımları, elastik modülleri ve kayma şekil değişimleri karşılaştırılmıştır. Hibrid nanoyapıştırıcı sistemlerin kırılma analizi, taramalı elektron mikroskobu (SEM) kullanılarak incelenmiştir. Farklı şekil ve boyutlardaki nano malzemelerin kırık yüzeylerde, destekledikleri farklı enerji dağıım mekanizmaları nedeniyle belirgin özellikler sunduğunu mikroyapıları ortaya çıkarmıştır. Modifiye edilmiş epoksi yapıştırıcıların termogravimetrik analizi (TGA) ile bozunma sıcaklıkları, termal kararlıı̆ı ve kalan kütle miktarları karakterize edilmiştir.

\section{Shear strength of boron nitride nanoplatelets and nano Ag reinforced structural adhesives}

\section{ARTICLE INFO}

Articl history:

Received 20 May 2019

Revised form 10 September 2019

Accepted 11 September 2019

Available online 30 September 2019

Research Article

DOI: $10.30728 /$ boron.568138

\section{Keywords:}

Single lap joints,

Shear strength,

Nanoparticles,

Hybrid nanoadhesive.

\begin{abstract}
In this study, shear strength of epoxy adhesives with hybrid nanoparticle reinforcement of various component structures used in aircraft was investigated. 8 layer $0^{\circ} / 90^{\circ}$ flat woven carbon fabric hand depositing technique vacuum system is produced with a thickness of $1.7 \pm 0.1 \mathrm{~mm}$. Produced carbon fibers reinforced epoxy composites (KETEK) and 2024-T3 Aluminum (AI) sheets were tested in accordance with ASTM D1002-10 standards as a one-sided overlap connection with modified epoxy adhesives. Al 2024T3 material ASTM D3933-98 phosphoric acid anodization and KETEK samples were used according to ASTM D2093-03 standards. To the epoxy resin was added $0.5 \mathrm{wt}$ \% Boron Nitride Nanoplatelets (BNNPs) and nano-silver (Ag) particles in different ratios $(0.5,1.0$, and $1.5 \%)$ by weight. The shear strength, elasticity modulus and slip pattern changes of the hybrid nanoparticles and reference samples were compared. Fracture analysis of hybrid nanoadhesive systems was investigated using scanning electron microscopy (SEM). The microstructures revealed that nanomaterials with different shapes and dimensions provide distinct features on the fracture surfaces due to the different energy dissipation mechanisms, which they support. The thermogravimetric analysis (TGA) of the modified epoxy adhesives was characterized by decomposition temperatures, thermal stability and residual mass quantities.
\end{abstract}

\section{Giriş (Introduction)}

Yapıştırıcıyla bağlanmış bağlantılar, havacılık ve diğer mühendislik uygulamalarında mekanik bağlantı yerlerine alternatifleri artırmakta ve geleneksel mekanik sızdırmazlığa göre birçok avantajlar sağlamaktadır. Yapısal yapıştırıcı yapıştırmada en yaygın kullanılan yüzeyler ahşap, alüminyum, titanyum, paslanmaz çelik ve yapıştırılmış sandviç yapıları, elyafla takviyeli plastik laminatlar gibi kompozit malzemeleri ve alüminyum elyaf/metal matris laminatları birleştirmek için epoksi gibi polimer yapıştırıcılar yaygın olarak kullanılmaktadır [1]. Özellikle havacılık uygulamalarında kullanılan kompozit parçaların birleştirilmesinde epoksi 
yapıştırıcıyla bağlamanın kullanılması, düşük maliyet, yüksek dayanım/ağırlık oranı, düşük gerilme dağılımı, daha az işlem süreçleri, üstün yorulma direnci ve korozyon direnci gibi birçok avantaj sağlar [2].

Epoksiler, uçak parçaları, borulardaki korozyon önleyici kaplamalar ve elektronik aygıtlar gibi yapıştırıcı olarak birçok mühendislik uygulamasında yaygın olarak kullanılmıştır [3]. Ancak epoksilerin düşük dayanımları ve toklukları, birçok durumlarda kullanımlarını sınırlamaktadır. Dolasıyla yapısal bileşenlerin bağlanması ve birleştirilmesinde, yapıştırılan metal malzemelerin yüzeylerin ön işlemleri [4] ve epoksi polimere dolguların dâhil edilmesi performansı arttırmanın en yaygın yoludur [5]. Yapıştırılan malzemelerin yüzey ön işlemleri karmaşık olup, çoğu zaman doğru süreç kontrolü gerektiren kimyasal reaksiyonları içerir. Buna karşılık yapıştırıcıya karbon nanotüp $[6,7]$, nano alümina [8], nano $\mathrm{TiO}_{2}$ [9], grafen [10], bor nitrür nanoplateler $[11,12]$ gibi nanoparçacıkların eklenmesi mekanik özelliklerin iyileştirilmesin de basit bir çözümdür.

Scarselli, Corcione, Nicassio ve Maffezzoli [13] epoksi ve nano grafit takviyeli epoksi yapıştırıcılarıyla karbon elyaf takviyeli kompozit malzeme ile Al 2024-T3 alaşımını tek taraflı bindirmeli bağlantı yaparak hem deneysel hem de nümerik olarak mekanik özelikleri incelemişlerdir. Bu araştırma kayma dayanım ve enerji emilimi açışından nano grafit takviyesinin epoksi yapıştırıcıya üstün mekanik özellikler kattığını göstermektedir. Nano grafit takviyeli epoksi ile referans numunesinin kayma dayanımı ve enerji emilimi sırasıyla $\% 18$ ve \%54 oranlarında artmıştır. Böylece nümerik ve deneysel sonuçlar arasında iyi bir ilgileşim sağlanmış ve yapıştırıcı hatasının doğrusal olmayan modellerini güvenilir ve doğru kriterleri belirlenmiştir.

Neto, da Cruz and Avila [14] nanoparçacıklarla takviye edilmiş yapıştırıcıların iyileştirilmesini ve performanslarını araştırmışlardır. Yapıştırılan malzeme olarak 10 tabaka karbon elyaf takviyeli epoksi kompozit, AR300 epoksi de yapıştırıcı olarak kullanılmıştır. Epoksi yapıştırıcıya, nanoparçacık olarak ağırlıkça \%1 ve 2 grafen ilave edilmiştir. Sonuçlar ağırlıkça \%1 grafen takviyeli epoksi yapıştırıcının maksimum yükü \%21 artarken, \%2 grafen takviyeli epoksinin ise \%57 oranında arttırmıştır.

Bu çalışmada, yapıştırıcıyla bağlanmış tek tarafı kompozit/alüminyum bindirmeli bağlantıların hasar yükünü arttırmak için yapıştırıcıya nanoparçacıklar eklenmiş olup, tek taraflı bindirmeli bağlantıların sabit yük altında çekme hasar yükleri deneysel olarak incelenmiştir.

\section{Malzemeler ve yöntemler (Materials and methods)}

\subsection{Malzemeler (Materials)}

Ortalama 100 nm çapında ve \%99,1 üzerindeki saflıkta hekzagonal formda Bor Nitrür Nanoplateler (BNNPs) Bortek firmasından ve $40 \pm 10 \mathrm{~nm}$ ortalama çapında sahip Ag nanoparçacıklar \%99,9 saflıkta ve küresel form da olup Nanografi'den temin edildi. Havacılık sertifikasına sahip ve infüzyon uygulamalarında rahatlıkla kullanılabilen $1,13-1,16 \mathrm{~g} / \mathrm{cm}^{3}$ yoğunluğunda, $700-900$ mPas viskoziteli MGS-L160® diglisidil eter bisfenol-A (DGEBA) reçine ve 0,96-1,0 g/ $\mathrm{cm}^{3}$ yoğunluğunda, 10 50 mPas viskoziteli MGS-H160® kürleştirici Momentive (Hexion)'dan satın alındı. Ayrıca 0/90º̈rgü, 210 teks ve $0,25 \mathrm{~mm}$ kalınlığında karbon elyaf kumaşlar Techel firmasından ve Al 2024-T3 plakalar Türk Havacılık ve Uzay Sanayii A.Ş. (TUSAŞ)'tan temin edildi.

\subsection{Karbon elyaf takviyeli epoksi kompozitlerin üretimi (Production of carbon fiber reinforced epoxy composites)}

Tipik uçak gövdelerindeki mevcut katman sayıları (8-16) [15] dikkate alınarak kompozitlerin 8 tabakalı olması öngörüldüğü için karbon elyaf kumaştan 320 mm x 320 mm ölçülerde 8 adet olacak şekilde

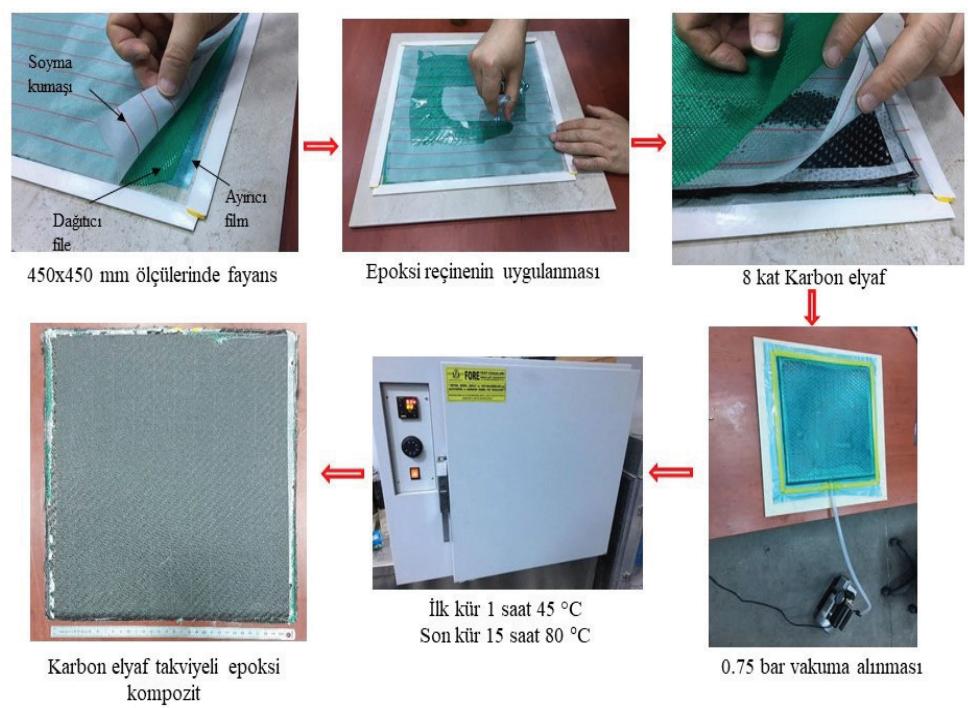

Şekil 1. Vakum yardımlı el yatırma yöntemiyle KETEK levhaların üretimi (Production of KETEK sheets by vacuum assisted hand lay-up method). 
kesilmiştir. 450 mm x 450 mm ölçülerindeki bir fayansın üzerine kalıp ayırıcı sürülmüştür. Fayansın üzerine karbon elyaf kumaşların yerleştirileceği yerin etrafına hava sızdırmazlığını sağlayan çift taraflı sızdırmaz bant yapıştırılmıştır. Ardından ayırıcı film, dağıtıcı file ve soyma kumaşı yerleştirilerek hazırlanmıştır. Önceden kesilen 8 kat karbon elyaf kumaşlar terazide tartılmıştır. Elyaf/matris oranı 0,45 olacak şekilde tartılan bu miktar ile hesaplanarak epoksi + kürleştirici (100/25 oranında) miktarı bulunmuştur.

Hazırlanan epoksi reçine ayırıcı kumaşın üzerine belirli bir miktar dökülerek spatula yardımı ile homojen olarak uygulanmıştır. Bu tabakaların üzerine önceden hazırlanan 320 x 320 mm ölçülerinde 1 kat karbon kumaş yerleştirilerek aynı şekilde karbon elyaf kumaşın üzerine belirli bir miktar dökülerek spatula yardımı ile homojen olarak uygulanmıştır. 8 kat karbon elyaf kumaşa bu şekilde epoksi reçine uygulaması yapılmıştır. Karbon elyaf kumaşların üzerine tekrar soyma kumaşı ve dağıtıcı file serilmiştir. Son olarak tüm tabakaların üzerine vakum torbası serilerek aralıklı olarak 0,75 bar vakuma alınmıştır. Daha sonra vakuma alınan kompozit malzeme fırında ilk kürleştirme işlemi için 1 saat $45^{\circ} \mathrm{C}$ 'de bekletilmiştir. Son kürleştirme işlemi için ise 15 saat $80^{\circ} \mathrm{C}$ 'de yapılarak numune üretimi gerçekleştirilmiştir (Şekil 1).

Kürleştirme işlemleri tamamlanan kompozit malzeme fayans üzerinden çıkarılmış ve üzerindeki ayırma kumaşıyla birlikte diğer kısımlarıda sökülmüştür. Kompozit levhalar yüksek hızlı dairesel bir testere ile 101,5 x 25 mm kesilerek yapılacak testler için gereken boyutlara getirilmiştir. KETEK malzemeler 1,7 $\pm 0,1 \mathrm{~mm}$ kalınlığında üretimi yapılmıştır.

\subsection{BNNPs ve nano Ag yapıştırıcıların hazırlanması (Preparation of BNNPs and nano $\mathrm{Ag}$ adhesives)}

Şekil 2'de hibrid nanoyapıştırıcıların hazırlanması şematik olarak verilmiştir. Epoksi reçine belirlenen oranda tartıldı. Bu oranın ağırlıkça \%0,5, 1,0 ve 1,5 oranlarında nano Ag, ağırlıkça \%0,5 oranındaki BNNPs ile farkI beherlerde birleştirildi. Problu homojenizatörle 10'ar dakika süreyle 3 defa olmak üzere toplam 30 dakika buz banyosu içinde yaklaşık oda sıcaklığı muhafaza edilerek karıştırıldı. Burada buz banyosu ve aralıklarla karıştırmamız sebebi nanoparçacıkların zarar görmemesi içindir. Sonra hazırlanan bu nano katkılı yapıştırıcı karışımı vakum fırını içerisinde oda sıcaklığında 5'er dakika ile kademeli olarak 0,25, 0,50 ve 0,75 bar vakumda bekletilerek karışım içindeki hava kabarcıkların giderilmesi sağlandı. Epoksi/kürleştirici 100/25 oranında ilave edilerek mekanik olarak hava kabarcığı olmayacak şekilde 10 dakika yavaş karıştırılarak hibrid nanoyapıştırıcılar hazırlanmıştır (Çizelge 1).

\subsection{Yapıştırılan malzemelerin yüzeylerinin hazır- lanması (Preparation of adherendsurfaces)}

Tek taraflı bindirmeli bağlantıların test numunesi boyutları ASTM D1002-10 standartlarına göre belirlenmiştir. Bu standartlara göre alüminyum levha ilk olarak $101,5 \times 25,00 \mathrm{~mm}$ boyutlarında bilgisayarlı sayısal kontrollü (CNC) lazer kesim tezgâhında ve KETEK levhaları yüksek hızlı elmas uçlu dairesel bir testere ile kesilmiştir. Kesim aşamasından sonra Al malzemelerin kenarlarında oluşan kalıntılar, yapışmayı etkileyebileceği ve çalışana zarar verebileceğinden dolayı ince eğe ile eğelenmiştir. Numunenin kenar kısımlarındaki pürüzler giderildikten sonra havacılık sektöründe

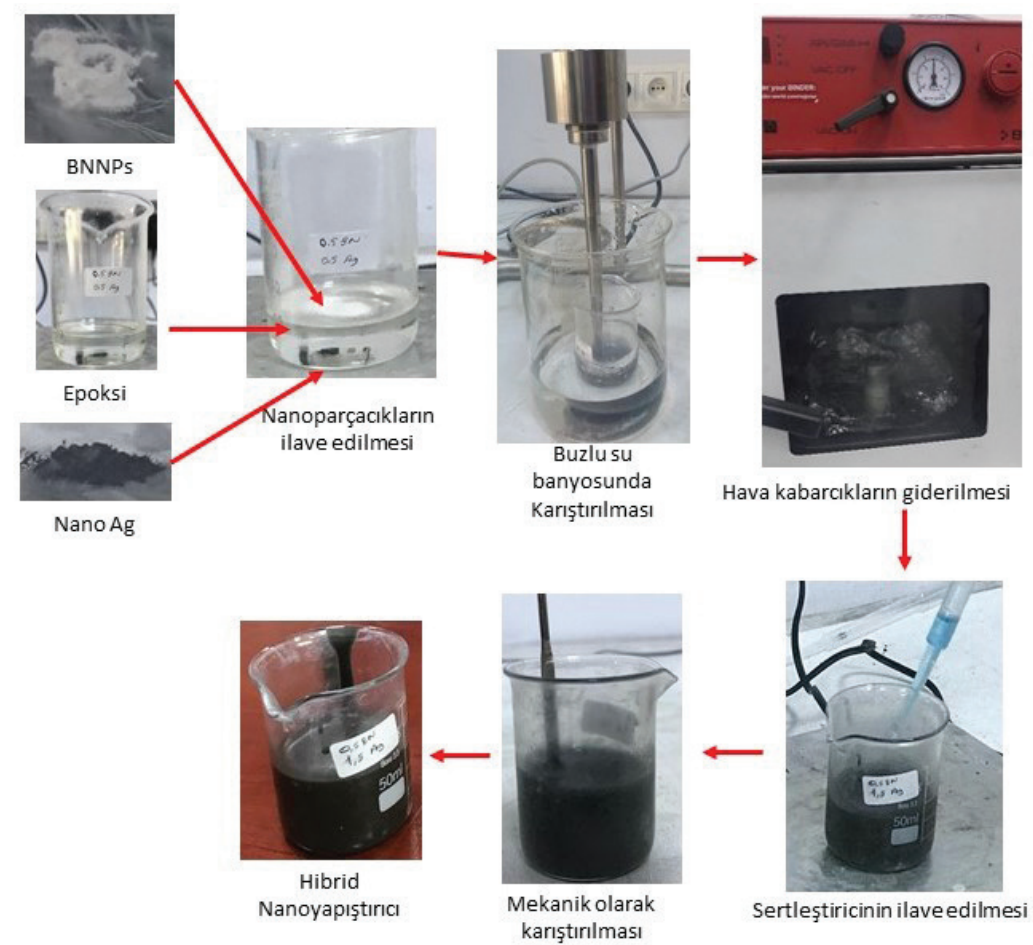

Şekil 2. BNNPs ve nano Ag yapıştırıcıların hazırlanması (Preparation of BNNPs and nano Ag adhesives). 
Çizelge 1. Hibrid nanoyapıştırıcıların ağırlıkça \% içeriği (\% By weight content of hybrid nanoadhesives).

\begin{tabular}{cccc}
\hline Numuneler & BNNPs & Nano Ag & $\begin{array}{c}\text { Epoksi + } \\
\text { Sertleştirici }\end{array}$ \\
\hline E & 0,0 & 0,0 & 100,0 \\
0,5 BNNP + 0,5 Nano Ag & 0,5 & 0,5 & 99,0 \\
0,5 BNNP + 1,0 Nano Ag & 0,5 & 1,0 & 98.5 \\
0,5 BNNP + 1,5 Nano Ag & 0,5 & 1,5 & 98,0 \\
\hline
\end{tabular}

en çok kullanılan yüzey hazırlama metodu olan ASTM D2651-01 standardına uygun (sülfürik asit/sodyum dikromat) çözeltisi ile ASTM D3933-98 standardına uygun yüzey temizleme işlemi yapılmıştır. Bu işlemler boyunca ve bittikten sonra yapıştırılacak yüzeylere çözelti suları ve yıkama işlemleri dışında dışarıdan herhangi bir temasta bulunulmamıştır. Yine aynı şekilde fosforik asitle anotlama işlemi sırasında ve sonrasında da yapıştırılacak yüzeylere temas edilmeden hızlı bir şekilde Şekil 3'teki işlem basamakları takip edilmiştir.

Fosforik asit anotlamanın ardından fırında kuruttuktan sonra 72 saat içinde yapıştırma işlemi uygulanmalıdır. Parçaları anotlama öncesi sınırlı bir kirlilik alanda yapılması gerekir ve ele alınmamalıdır.

Al parçaların yüzey pürüzlülük Ra ve Rz değerleri Mitutoyo SJ-301 cihazı kullanılarak 7 mm'lik mesafe ölçülmüş olup, sırasıyla 2,18 $\pm 0,04$ ve 16,81 $\pm 1,05 \mu$ m'dir.

KETEK malzemelerden kesilen levhalar ASTM D 2093 standardına göre yüzey hazırlama işlemleri uygulanmıştır. Levhalar ilk olarak su ile yıkanmıştır. Daha sonra yüzeylerin aşındırılması için 320 nolu SiC zımpara ile mekanik olarak yüzey pürüzlülüğü oluşturulmuştur.
Yüzey pürüzlülük değeri Ra 1,85 $\pm 0,12 \mu \mathrm{m}(7 \mathrm{~mm}$ boyunca) olarak ölçülmüştür. Levhaların yüzeyinde bulunan kirlilik veya zımparama işleminden oluşan parçacıkları temizlemek için aseton içinde ultrasonik banyoda 30 dakika bekletilmiştir.

\subsection{Tek tarafı bindirmeli bağlantıların hazırlanması (Preparation of single lap joints)}

Numuneler Şekil 4'te görüldüğü gibi ilk önce 20 mm yapıştırma uzunluğunda olacak şekilde kalıp boyutları hazırlanmıştır. Al numunenin uç kısmına 20 mm'lik nanoyapıştırıcı sürülerek kalıba yerleştirildikten sonra diğer tarafına yapıştırma kalınlığı 0,20 mm olacak şekilde mastar konulmuştur. Hazırlanan hibrid nano yapıştırıcılar, karbon elyaf takviyeli epoksi kompozit ile Al numunelerin yapıştırılacak yüzeylerine spatula yardımıyla sürülmüştür. Kompozit ve Al numunelerin yapışma yüzeyleri üst üste gelecek şekilde yerleştirilerek kalıbın üst taraftaki vida ile $15 \mathrm{kPa}$ basınçla 24 saat oda sıcaklığında bekletilerek yapışma bağlantısı gerçekleştirilmiştir. Son kürleştirme işlemi için $80^{\circ} \mathrm{C}$ 'de 15 saat vakum fırınında bekletilerek yapıştırma işlemi tamamlanmıştır.

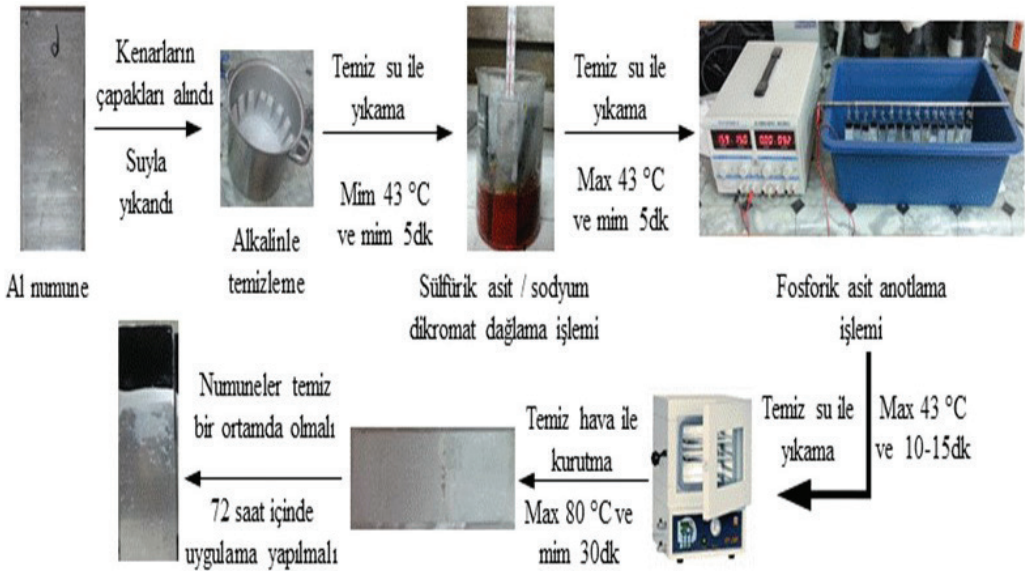

Şekil 3. Alüminyum bağlantı numunelerin yüzey hazırlama işlemleri (Surface preparation of aluminum joints samples).

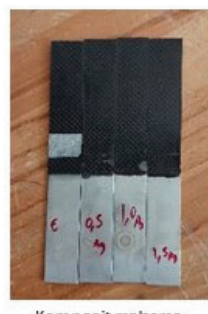

Kompozit malzeme

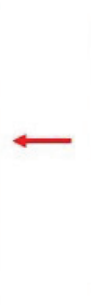

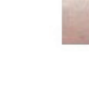
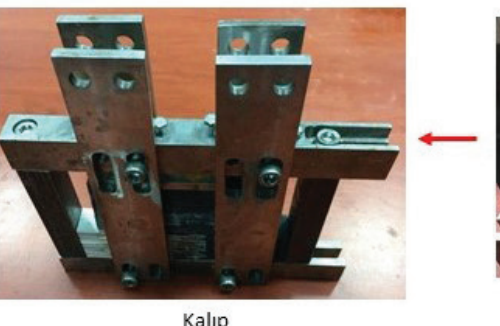

Kalıp

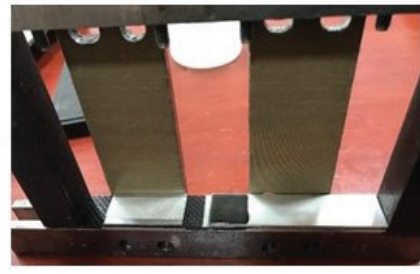

Kalıba yerleştirilmesi ve mastar verlestirilmesi

Şekil 4. Tek taraflı bindirmeli bağlantının yapıştırma kalıbına yerleştirilmesi (Placing of the single lap joint into the adhesive mold). 


\subsection{Karakterizasyon (Characterization)}

TGA termal analiz ölçümleri, Necmettin Erbakan Üniversitesi Bilim ve Teknoloji Araştırma ve Uygulama Merkezinde (BITAM) Setaram-Labsys Evo marka cihazında $0,02 \mathrm{~g}$ ağırlık ve $0,1^{\circ} \mathrm{C}$ sıcaklık ile yapılmıştır. Termal kararılık, bozunma sıcaklıkları ve artık kütle TGA ile analiz edilmiştir. Test numuneleri bir azot atmosferi altında $10^{\circ} \mathrm{C} /$ dakikalık bir ısıtma hızında $25^{\circ} \mathrm{C}$ ila $620^{\circ} \mathrm{C}$ 'ye ısıtılmıştır.

Hibrid nanoyapıştırıcı numunelerinin çekme testleri Shimadzu AGS-X test cihazında ASTM D1002-10 standardına uygun olarak $2 \mathrm{~mm} /$ dakika çekme çene hızında gerçekleştirilmiş olup numunelerin uzamaları Eplison 3560 model iki eksenli dinamik ekstansometre ile ölçülmüştür. Her bir numuneye uygulanan kuvvet $P$ ve yer değiştirme $\delta$ değerleri anlık olarak kayıt edilmiş ve numunelerin kayma gerilmesi, kayma birim şekil değişimi ve kayma modülü hesaplanmıştır.

\section{Sonuçlar ve tartışma (Results and discussion)}

\subsection{Hibrid nanoyapıştırıcıların TGA analizleri (TGA analysis of hybrid nanoadhesives)}

Hibrid nanoyapıştırıcıların ve saf epoksi yapıştırıcının TGA analiz sonuçları Şekil 5'te verilmektedir. Sırasıyla \%5, \%50 kütle kaybı ve tamamen bozunmanın gerçekleştiği sıcaklıklar saf epoksi için sırasıyla 287, 330 ve $550^{\circ} \mathrm{C}$ 'dir. Hibrid nanoyapıştırıcıların \%5 ile $\% 50$ kütle kaybı hemen hemen aynıdır. Fakat tamamen bozunma sıcaklıkları 0,5 BNNP + 0,5 Nano Ag, 0,5 BNNP + 1,0 Nano Ag ve 0,5 BNNP + 1,5 Nano Ag kompozitlerin sırasıyla $540^{\circ} \mathrm{C}, 520^{\circ} \mathrm{C}$ ve $500^{\circ} \mathrm{C}$ olarak tespit edilmiştir.
Nanoparçacık sayısı sızma eşiği değerine ulaştıktan sonra nanoparçacıklar topaklanmaya başlayarak matris-nanoparçacık arasındaki bu etkileşim azalmaktadır. Topaklanmanın sistemde kirlilik olarak işlev gördüğü nanoparçacık oranında termal kararlılık sıcaklığını azaltmaktadır [16].

Kalıntı kütle miktarları epoksi yapıştırıcının \%11,8 iken 0,5 BNNP + 1,5 Nano Ag yapıştırıcının \%15,5'dir, nanoparçacıkların ilave edilmesiyle kalıntı kütle miktarları artmıştır (Çizelge 2).

\subsection{Tek tarafı bindirmeli bağlantıların test sonuçları (Test results of single lap joints)}

Saf epoksi reçine ve hibrid katkılı epoksi yapıştırıcının tek taraflı bindirmeli bağlantılarının yük-uzama eğrileri Şekil 6'da verilmiştir. Saf epoksini maksimum yükü $4668 \mathrm{~N}$ iken, 0,5 BNNP + 0,5 Nano Ag yapıştırıcının $\% 18$ artış ile 5499 N'da gerçekleşmiştir.

Hibrid nanoyapıştırıcıların kayma dayanımları ve kayma birim şekil değiştirme miktarındaki değişimler, malzemenin kopana kadar yuttuğu toplam enerjiyi yani nanoparçacıklarla takviyeli epoksi yapıştırıcıların tokluğunu nasıl etkilediği sorusunu akla getirmektedir. Çekme testlerinde tokluk, kayma gerilmesi - kayma birim şekil değiştirme eğrisinin altında kalan alan olarak hesaplanır. Numunelerin tokluk değerleri, kayma dayanımı ve kayma modülü Çizelge 3'tedir. En büyük tokluk artışı epoksi yapıştırıcıyla karşılaştırıldığında \%61 artış ile 0,5 BNNP + 0,5 Nano Ag takviyeli hibrid yapıştırıcıda $878,1 \mathrm{~kJ} / \mathrm{m}^{3}$ olarak hesaplanmıştır. Nanoparçacıkların epoksi matriks içerisine ilave edildiği zaman hem kayma dayanımının hem de kayma birim şekil değiştirme miktarının artmasını sağlayarak epoksi yapıştırıcının tokluğunu da iyileştirmiştir. Fakat

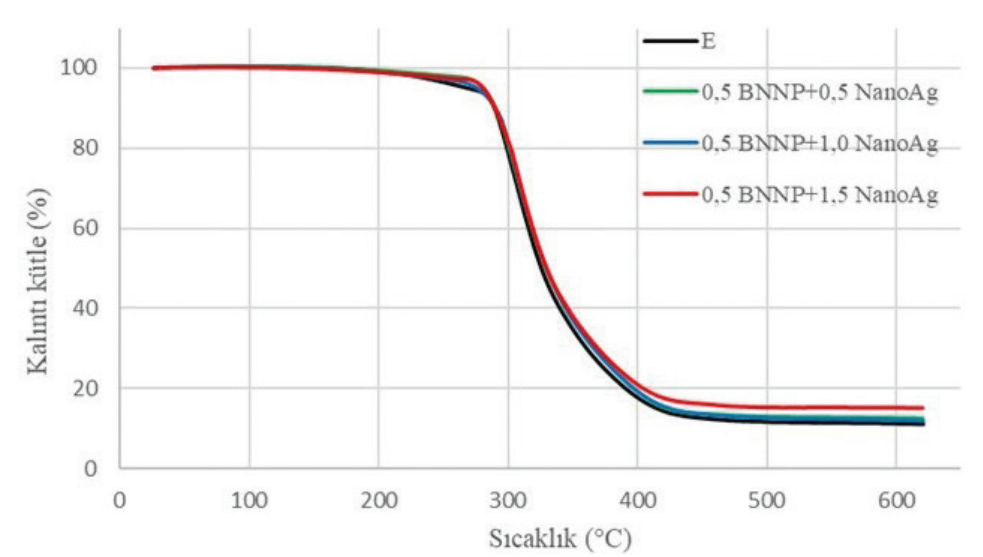

Şekil 5. Hibrid nanoyapıştırıcıların TGA eğrileri (TGA curves of hybrid nanoadhesives).

Çizelge 2. Hibrid nanoyapıştırıcıların ısıl analiz değerleri (Thermal analysis values of hybrid nanoadhesives).

\begin{tabular}{|c|c|c|c|c|c|c|}
\hline \multirow[b]{2}{*}{ Numuneler } & \multicolumn{3}{|c|}{ Bozunma sıcaklıkları $\left({ }^{\circ} \mathrm{C}\right)$} & \multirow{2}{*}{$\begin{array}{l}\text { Kalan kütle } \\
\text { miktarı (\%) }\end{array}$} & \multirow[b]{2}{*}{$T_{g}$} & \multirow[b]{2}{*}{$\mathbf{T}_{\mathrm{m}}$} \\
\hline & $\% 5$ & $\% 50$ & $\begin{array}{c}\text { Max } \\
\text { bozunma }\end{array}$ & & & \\
\hline $\mathbf{E}$ & 287 & 330 & 550 & 11,8 & 73,5 & 287,5 \\
\hline 0,5 BNNP + 0,5 Nano Ag & 286 & 330 & 540 & 12,2 & 62,2 & 287,2 \\
\hline 0,5 BNNP + 1,0 Nano Ag & 286 & 331 & 520 & 13,1 & 61,7 & 287,5 \\
\hline 0,5 BNNP + 1,5 Nano Ag & 285 & 332 & 500 & 15,5 & 62,7 & 287,5 \\
\hline
\end{tabular}




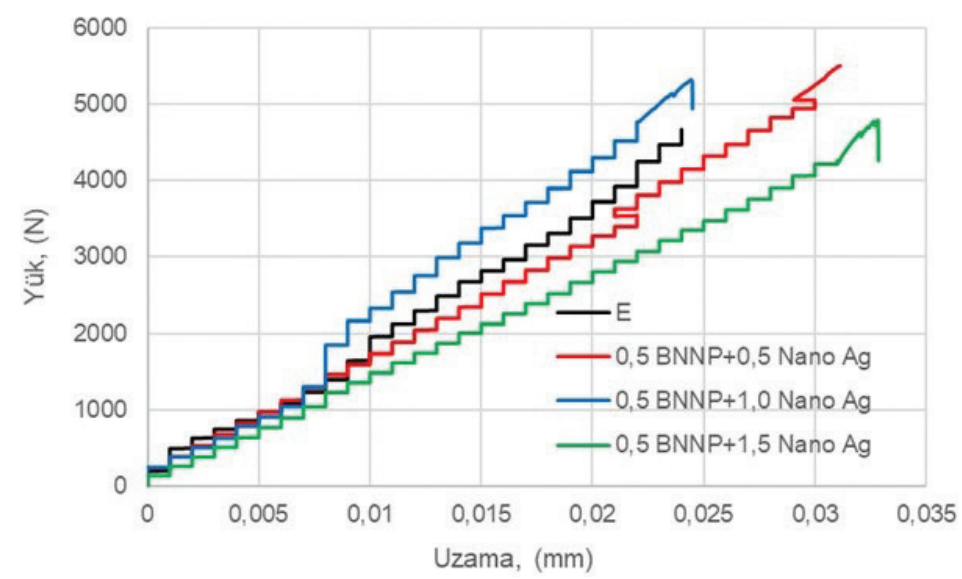

Şekil 6. Tek taraflı bindirmeli bağlantıların yük-uzama grafiği (Load-elongation graph of single lap joints).

Çizelge 3. Hibrid nanoyapıştırıcıların mekanik özellikleri (Mechanical properties of hybrid nanoadhesives).

\begin{tabular}{cccccc}
\hline Numuneler & $\begin{array}{c}\text { Maks. } \\
\text { Yükleme } \\
(\mathbf{N})\end{array}$ & $\begin{array}{c}\text { Kayma } \\
\text { dayanımı, } \\
(\mathbf{M P a})\end{array}$ & $\begin{array}{c}\text { Kayma } \\
\text { şekil } \\
\text { değişimi, } \\
(\mathbf{m m} / \mathbf{m m})\end{array}$ & $\begin{array}{c}\text { Tokluk, } \\
\left.(\mathbf{k J / m})^{3}\right)\end{array}$ & $\begin{array}{c}\text { Kayma } \\
\text { modülü, } \\
(\mathbf{G P a})\end{array}$ \\
\hline $\mathbf{E}$ & 4667,7 & 9,11 & 0,12 & 546,5 & 0,98 \\
$\mathbf{0 , 5}$ BNNP + 0,5 Nano Ag & 5499,2 & 11,28 & 0,16 & 878,1 & 0,85 \\
$\mathbf{0 , 5}$ BNNP + 1,0 Nano Ag & 5319,1 & 10,64 & 0,12 & 651,5 & 1,30 \\
$\mathbf{0 , 5}$ BNNP + 1,5 Nano Ag & 4787,9 & 9,58 & 0,16 & 786,5 & 0,67 \\
\hline
\end{tabular}

nanoparçacık miktarı ıslanma eşiğini geçtikten sonra topaklanarak iyi ıslanamadıkları için nanoçatlaklar oluşumuna ortam hazırlamaktadır [17].

\subsection{Hibrid nanoyapıştırıcıların SEM görüntüsü (SEM image of hybrid nanoadhesives)}

BNNPs ve nano Ag takviyeli epoksi yapıştırıcılara ait çekme deneyinden sonraki kırılma yüzeylerinin mikroyapıları Şekil 7'dedir. Tek taraflı bindirmeli bağlantıların kırılma yüzeyleri, kırılma davranışlarında hibrid nanoparçacıkların modifikasyonun etkileri ve kırılma mekanizmaları hakkında ilk bilgiyi verir [18]. Epoksi reçinenin kırılma yüzeyleri incelendiğinde tipik gevrek kırılma sürecinde olduğu gibi yüzey daha düz ve pürüzsüzdür (Şekil 7a). Fakat Şekil 7b, c ve d'de gösterildiği gibi BNNPs ve nano Ag takviyeli epoksi yapıştırıcıyla bağlanmış bağlantıların kırılma yüzeyleri ise nehir akıntıları gibi yapılar nispeten pürüzlü ve parçacıklıdır.

BNNPs ve nano Ag sıyrılması ve köprülenme gibi çatlak ucunun yön değiştirmesi veya çatallanması nanoparçacıklarla takviye edilmiş epoksi yapıştırıcılarda gözlenen önemli tokluk mekanizmalarıdır [19,20]. Bu mekanizmalar, ağırlıkça \%0,5 BNNPs ve \%0,5 nano Ag oranlarındaki epoksi yapıştırıcının kırılması epoksi
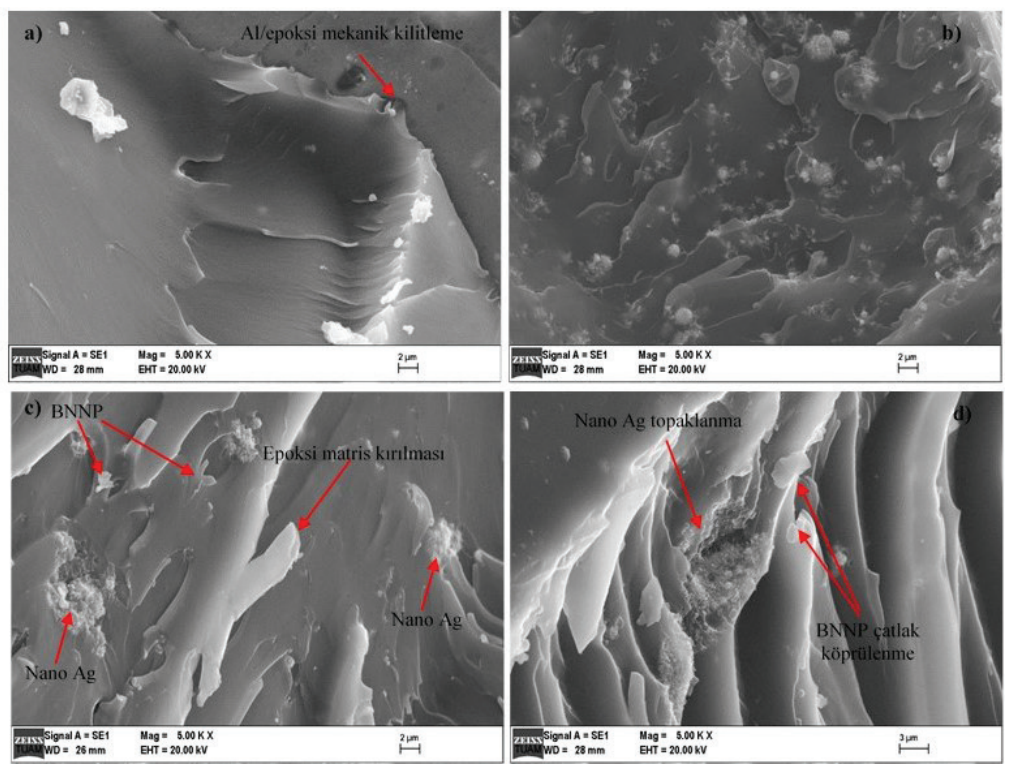

Şekil 7. Hibrid nanoyapıştırıcıyla bağlanmış tek taraflı bindirmeli bağlantıların SEM görüntüleri: a) E, b) 0,5 BNNP + 0,5 Nano $\mathrm{Ag}, \mathrm{c})$ 0,5 BNNP + 1,0 Nano Ag ve d) 0,5 BNNP + 1,5Nano Ag (SEM images of single lap joints bonded with hybrid nanoadhesive: a) E, b) $0.5 \mathrm{BNNP}+0.5 \mathrm{Nano} \mathrm{Ag}$, c) $0.5 \mathrm{BNNP}+1.0 \mathrm{Nano} \mathrm{Ag}$ ve d) $0.5 \mathrm{BNNP}+1.5 \mathrm{Nano} \mathrm{Ag}$ ). 
reçinenin kırılması için gerekli olan enerjiden daha fazla enerjiye intiyaç olduğunu göstermiştir. Aynı zamanda bu orandaki nanoparçacıklar homojen bir dağılım göstermiştir (Şekil 7b). Bu şekilde modifiye edilmiş yapıştırıcı matrikste kırılma yüzeyleri arasında ilerleyen çatlağı köprülenme etkisiyle durdurduğu veya çatlağın dallandığı söylenebilir. Fakat nanoparçacık miktarının artmasıyla hibrid nanoyapıştırıcıda Şekil 7c ve d'de görüldüğü gibi topaklanmanın attığı ve ıslanabilirliğin düştüğü görülmektedir [21]. Bu yüzden sızma eşiği miktarından sonra ilave edilen nanoparçacıklar mekanik özellikleri düşürmüştür.

\section{Sonuçlar (Conclusions)}

Bu çalışmada, alüminyum-karbon elyaf takviyeli epoksi kompozit levhalar tek taraflı bindirme bağlantılarında farklı oranlarda nanoparçacıkların epoksi reçinenin içerisine ilave ederek hibrid nanoyapıştırıcının mekanik özelliklerini geliştirmek için bir metodoloji önerilmiştir. Hibrid nanoyapıştırıcının üretiminde, nano boyuttaki mükemmel özellikli BNNPs ve nano Ag dolgu maddelerinin kullanılması, yüksek mekanik özelliklere sahip epoksi bazlı BNNPs ve nano Ag takviyeli yapıştırıcılar elde edilmesini sağlamıştır.

0,5 BNNPs + 0,5 nano Ag hibrid nanoparçacıklı epoksi yapıştırıcıların sabit yük altındaki çekme testleri sonucunda kayma dayanımı ve tokluğu, epoksi reçine ile karşılaştırıldığı zaman sırasıyla \%18 ve 61 oranlarında artmıştır. Böylece nanoparçacık modifikasyonunun, tokluk artışını sağlamak için kullanılabileceği sonucunu göstermiştir. Nanoparçacık miktarının artırılması, sızma eşiğinden sonra nanoparçacıklarda topaklanmanın artması ve ıslanabilirliliğin azalmasından dolayı mekanik özelliklerin düşmesine yol açmıştır.

Isıl analizler sonucunda nanoparçacıkların artmasıyla sistemde ikincil bir ısı kaynağı vazifesi görerek ısıl bozunma sıcaklıklarını düşürmüştür.

\section{Kaynaklar (References)}

[1] Bishopp J., 13 - Adhesives for Aerospace Structures, Handbook of Adhesives and Surface Preparation, S. Ebnesajjad, ed., William Andrew Publishing, Oxford, pp. 301-344, 2011.

[2] Vietri U., Guadagno L., Raimondo M., Vertuccio L., Lafdi,K., Nanofilled epoxy adhesive for structural aeronautic materials," Compos. PartB-Eng, 61, 73-83, 2014.

[3] Pethrick R. A., Design and ageing of adhesives for structural adhesive bonding - A review, P I Mech Eng L-J. Mat., 229 (5), 349-379, 2015.

[4] Kang J. H., Siochi E. J., Penner R. K., Turner, T. L., Enhanced adhesive strength between shape memory polymer nanocomposite and titanium alloy, Compos. Sci. Technol., 96, 23-30, 2014.

[5] Yaman B., Açıkbaş N. Ç., Dry sliding behaviour of boron waste reinforced epoxy matrix composites, Boron, 3 (2), 63-70, 2018.

[6] Spitalsky Z., Tasis D., Papagelis K., Galiotis C., Carbon nanotube-polymer composites: Chemistry, pro- cessing, mechanical and electrical properties, Prog. Polym. Sci., 35 (3), 357-401, 2010.

[7] Hsiao K. T., Alms J., Advani S. G., Use of epoxy/multiwalled carbon nanotubes as adhesives to join graphite fibre reinforced polymer composites, Nanotechnology, 14 (7), 791-793, 2003.

[8] Jouyandeh M., Jazani O. M., Navarchian A. H., Saeb, M. R., High-performance epoxy-based adhesives reinforced with alumina and silica for carbon fiber composite/steel bonded joints J. Reinf. Plast. Comp., 35 (23), 1685-1695, 2016.

[9] Ghosh P. K., Kumar K., Preeti P., Rajoria M., Misra N., Superior dissimilar adhesive joint of mild steel and aluminium using UDM processed epoxy based $\mathrm{TiO}_{2}$ nano-filler composite adhesive, Compos. Part B-Eng., 99, 224-234, 2016.

[10] Reza Borghei H., Behjat B., Yazdani M., The impact of graphene nanoparticle additives on the strength of simple and hybrid adhesively bonded joints, J. Compos. Mater., 53 (23), 3335-3346, 2018.

[11] EkremM., DuzcukogluH., SenyurtM.A., SahinÖ.S.,Avci A., Friction and wear performance of epoxy resin reinforced with boron nitride nanoplatelets, J. Tribol., 2017.

[12] Efeoğlu İ., Totik Y., Keleş A., Ersoy K., Durkaya G., Synthesis and investigation of structural-mechanicaltribological properties of c-BN based BN thin films, Boron, 2 (1), 11-17, 2017.

[13] Scarselli G., Corcione C., Nicassio F., Maffezzoli A., Adhesive joints with improved mechanical properties for aerospace applications, Int. J. Adhes. Adhes., 75, pp. 174-180., 2017.

[14] Neto A. S., da Cruz D. T. L., Avila A. F., Nano-modified adhesive by graphene: The single lap-joint case, Mater Res-Ibero-Am J., 16 (3), 592-596, 2013.

[15] York C. B., On bending-twisting coupled laminates, Compos. Struct., 160, 887-900, 2017.

[16] Ghosh P., Pathak A., Goyat M., Halder S., Influence of nanoparticle weight fraction on morphology and thermal properties of epoxy/TiO nanocomposite, J. Reinf. Plast. Comp., 31 (17), 1180-1188, 2012.

[17] Li J., Ma P. C., Chow W. S., To C. K., Tang B. Z., Kim J. K., Correlations between percolation threshold, dispersion state, and aspect ratio of carbon nanotubes, Adv. Funct. Mater., 17 (16), 3207-3215, 2007.

[18] Gojny F. H., Wichmann M. H., Fiedler B., Schulte K., Influence of different carbon nanotubes on the mechanical properties of epoxy matrix composites-a comparative study, Compos. Sci. Technol., 65 (15), 2300-2313, 2005.

[19] Ekrem M., fracture behavior of epoxy adhesives reinforced with carbon nanotubes and polyvinyl alcohol nanofibers in aluminum joints," PhD Dissertation, Selcuk University, Konya, 2015.

[20] Ekrem M., Ataberk N., Avcı A., Akdemir A., Improving electricalandmechanical properties of a conductivenano adhesive, J. Adhes. Sci. Technol., 31 (7), 699-712, 2017.

[21] Ekrem M., Avcı A., Effects of polyvinyl alcohol nanofiber mats on the adhesion strength and fracture toughness of epoxy adhesive joints, Composites Part B: Engineering, 138, 256-264, 2018. 